\title{
Communicating through Vernacular Media: Scope and Challenges
}

\author{
A. Sule \\ Homi Bhabha Centre for Science Education, Tata Institute of Fundamental Research, \\ Mumbai, India, email: aniket.sule@gmail.com
}

India is a country with a large number of languages which not only differ in scripts but are essentially part of different language families. "Marathi" is one such Indian regional language spoken by nearly 70 million people and is the native language of the author. Like all major regional languages, there is a strong and vibrant media in Marathi with 45 odd newspapers and 6 television news channels.

India has a large student population with about half a million graduating with bachelors degree. However, India has only 220 IAU members. Also, in the demographics of professional astronomers, some languages are under-represented either due to cultural differences in communities or due to brain-drain or due to difference in opportunities and geographic distribution of astronomy institutions. In short, we have astronomers, we have press, but no communication between the two groups. Many astronomers don't know how to explain astronomy to non-experts. Further, the media bosses exhibit apathy towards science due to superstitious beliefs prevalent in society as well as fear of lack of viewers for serious content. Most journalists perceive astronomers as snobbish and they lack expertise to make sense of what the astronomer is saying.

The author has been residing for last six years in Mumbai, capital city of Marathi speaking Maharashtra state and home to studios of most major news channels (English, Hindi and Marathi). Astronomy expertise is available for media at TIFR $(\sim 20$ astronomers) and a planetarium. However, none of these experts are native Marathi speakers. Thus, media mostly depend on college physics teachers and amateur astronomers. After relocating to Mumbai the author has tried popularising astronomy at every possible opportunity like eclipses, the transit of Venus, India's moon mission and other satellite launches. The author spent about 20 hours on Marathi television channels, wrote more than 25 popular articles in Marathi for newspapers and magazines and gave about 30 popular talks (in Marathi and English) at schools and colleges.

A few key lessons can be learnt from these interactions with media. First, we should remain accessible and approachable and develop personal rapports with journalists. Second, the expert should understand the intended audience. Each media outlet has a target audience in mind and city readers/viewers have different sensibilities than hinterland readers/viewers. Similarly, viewers of vernacular language news channels expect content in a different format than English language news. Further, the choice of format of interaction and choice of media outlet is also important. Live newsbites require more skill, but give you more direct control over content. What you say cannot be re-edited by others. One should take into account past track record of a media outlet on science reporting and if it distorts the truth for sensationalisation. It helps if the expert also has some experience of working with camera/editing. Experts also must remember audiences for local media prefer local cultural context. 
To summarize, it is important to reach audience glued to local languages and dialects. A stark pointer of this reality is the fact that most students prefer conversing in their native language rather than language of instructions at the school. Strategies for teaching can be universal but localisation is essential and science communication resources developed in local languages have a possible application in respective migrant communities in developed countries. 